\title{
Research on Anxiety Control in Cooperative Learning of English
}

\author{
Wang Jing \\ Department of translation, \\ College of foreign languages Zhejiang International Studies University \\ Hangzhou 310023, China \\ zxdningbo@126.com
}

\begin{abstract}
This paper mainly discusses the students' general obstacle anxiety in the process of English learning. This kind of anxiety has a negative influence on target language learning. This paper proposes a language learning strategy based on constructivist learning theory, which uses cooperative learning theory and two language acquisition theories to solve these problems. Based on the "student centered" teaching concept, this paper puts forward some suggestions for English teaching. Teachers should pay full attention to emotional factors and individual differences in students' language learning. Students should be fully aware and sensitive to their emotional problems in their studies.
\end{abstract}

Keywords-anxiety controlling;constructiveness; second language acquisition; cooperative learning; Emotional factors; individual differences

\section{INTRODUCTION}

Anxiety is also called psychological abnormality. Anxiety is generally regarded as a state of anxiety or a state of fear that is threatened by failure to achieve or overcome the threat of an obstacle, a loss of self-esteem or self-confidence, or an increase in the sense of failure. The results show that affective factors are closely related to foreign language acquisition, among which anxiety is one of the most important affective factors $[1,2]$. Cooperative learning is a teaching theory and strategy system proposed by American Robert E.Slavin in the early 1970s and made substantial progress in the middle of 70s. This is a language learning strategy based on constructivist learning theory, which is one of the most pervasive and fruitful fields of language education theory and practice in recent years. Because of this kind of teaching idea in improving the psychological atmosphere of the classroom, a large area to improve the academic performance of students, promote students' good non intelligence quality development has obvious effect, soon attracted widespread attention all over the world, and has gradually become a mainstream teaching theories and strategies[3].

\section{ANALYSIS OF AFFECTIVE FACTORS IN ENGLISH LEARNING}

Affective disorder is like a wall that blocks language input and the mechanism of language acquisition (LAD).The higher the emotional barriers, the less information is input, reducing the processing and absorption function of the brain, so that the brain can't produce normal language output. Anxiety is one of the most important factors in emotional disorders. Anxiety has a serious negative impact on English teaching. "When anxiety is present in the classroom, there is a down-spiraling effect. Anxiety makes us nervous and afraid and thus contributes to poor performance; thus in turn creates more anxiety and even worse performance."(Amold, 1999:9)[4].In English learning process, anxiety is often due to students have high expectations of themselves, and after a long time or failed to achieve the desired goal, emotional will cause certain fluctuations. When the learner's self-assessment (the assessment of his English proficiency is lower than the actual level) is too low, it is also prone to mental depression. At present, a large number of experiments and studies have shown that high or low anxiety can seriously affect the learning effect. For a long time, the disadvantages of "examination oriented education" in China's foreign language teaching system have seriously hampered the development of students' practical language ability. At the same time, traditional foreign language teaching methods pay more attention to the teaching of language knowledge, but ignore the emotional needs of students as a person. When a student enters college, listening and speaking (especially in the face of foreign teachers) and writing, they can cause anxiety and anxiety (middle school is mainly for reading training). These factors are bound to seriously hinder them from achieving their desired results. Many foreign language teachers find out that college students generally have anxiety in their listening, speaking and writing studies [5,6]. The so-called "life oriented" teaching idea is to provide all the services for students. Therefore, it is necessary to carry out a series of reforms to the traditional teaching methods. This reform is not only content, but also should pay attention to students' emotional factors and individual differences. Different teaching methods should be carried out separately for different students.

\section{ANALYSIS OF THE CAUSES OF ANXIETY}

The causes of anxiety in the course of English learning may vary from person to person, but the main reasons are as follows:

\section{A. Students' reasons}

First of all, the students learn English listening and speaking as an example to illustrate the problem. Because students are accustomed to reading articles in middle school English learning, the main purpose of learning is to understand the meaning of the article. The teacher's lecture is explained in 
Chinese, and the form of the test is also written. The whole teaching objective is to enable students to cope with all kinds of tests, of course, mainly through the college entrance examination. In this course of English teaching, students do not need to understand English through their ears, nor do they need to express English through oral English, which eventually leads to the so-called "deaf English" and "dumb English". After entering the University, they face listening and speaking classes, especially when foreign teachers attend classes, they often get confused, and then feel anxious and uneasy. This situation is particularly evident for students from county or rural areas whose English teaching environment is relatively backward. They are worried about their ability to learn English well and are more prone to anxiety. In addition, the students' ability to "fault tolerance" in learning English should also be improved. "A degree of ambiguity-tolerance is essential for language learner."(Oxford, see Amold,1999:62). In secondary school learning, students are required to master and understand all the contents of the textbook.

However, students will find themselves frustrated and anxious when they find out what they often do not understand in college listening classes. [7]. Students often appear too low self-evaluation, easily lead to anxiety. And they usually don't have the ability to adjust to this emotion. "Those with high self-esteem might handle their anxiety better than those with low self-esteem, resulting in better performance." (Oxford,see Amold, 1999:62).

\section{B. Teacher factors}

English teachers often exhibit too much authority in their teaching. "Many language teachers maintain the belief that they should be directive, authoritarian and even intimidating."(Young,1991). In this case, when the students do not understand the content, but also can't easily ask the teacher. In this way, students are too nervous in class and can't concentrate on the content of the course itself. Teachers may sometimes show impatience with students who cannot answer questions, and may also increase student nervousness and anxiety, [8]. Therefore, the patience of teachers in the teaching process is also very important.

\section{Environmental factor}

The competition between students also causes one of the major causes of tension and anxiety. "Anxiety is aroused when language learners compare themselves to others, which can rarely attain."(Bailey,1983). Especially for freshmen who have just entered the University, they suddenly face the pressure of unprecedented competition, and start a new competition with other students in a new environment. Once they encounter setbacks or failures, they lose their sense of achievement and superiority in middle school. They will doubt their abilities and eventually feel lost and anxious. The method of scene teaching is mentioned, in this method, the ultimate goal of the learner is not limited to the retelling of the text, but also to the development of the story according to his own needs.

\section{CONTROLLABILITY OF LEARNING ANXIETY}

This section discusses whether or not the students' anxiety in the two language learning can be controlled and how well they can control it.

\section{A. The feasibility of controlling anxiety}

As early as in 1977, Gardner, Smythe and Brunet conducted successful experiments on anxiety control in the two language learning process. They treated three groups of students at a school in the United States with varying degrees of anxiety during school French classes. The combination of rational behavior therapy and the two language learning theory lasted two months of anxiety control, and the results showed that the students' anxiety in French class learning was obviously reduced. Through this series of experiments, it is proved that the anxiety in the two language learning can be controlled and reduced. Students who took the test agreed. A certain degree of psychological guidance and appropriate teaching methods can reduce the anxiety level of the two language learning.

\section{B. Control the level of anxiety relief}

The aim of controlling anxiety is to control the anxiety index of students in a suitable range, that is, $2.8 \sim 3.6$. When students' mental tension is within this range, they are most conducive to learning. In Gardner's experiment, carried out before treatment, the average sampling of the students is 3.64, after two months of treatment, their average index dropped to 2.94, which will be adjusted to the anxiety level of college students for learning within the scope of. The relation between anxiety and learning effect is shown in Fig. 1.

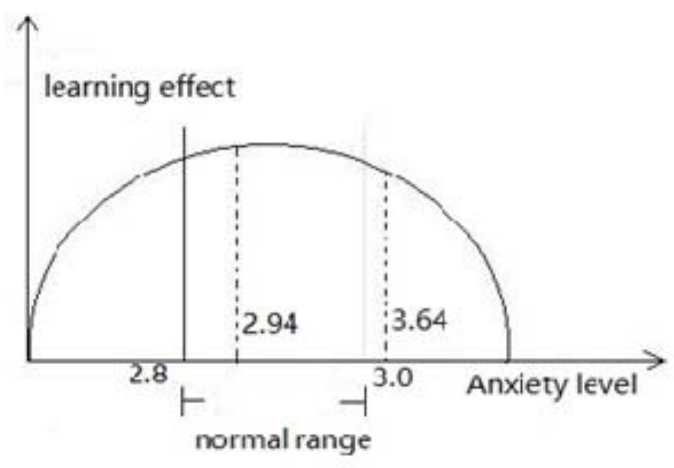

Fig. 1 Relationship between anxiety and learning efficiency

As you can see from the diagram, with the new teaching methods and some psychological counseling methods, most of the students have returned to the normal range of anxiety. That is to say, through effective means, the anxiety level of students in the two language learning process can be controlled to an ideal range.

Through the study of cognitive model, we can realize that knowledge can be transferred more effectively only when new knowledge is established on the basis of existing knowledge. These researches on the concept of autonomous learning are of great value in language teaching. This method of teaching shows that teachers are not only the teachers of knowledge, but also a kind of learning resources and suggestions. They require 
students to make a series of decisions by themselves. The discussion about learning autonomy has a more profound impact: changing the learning master - slave relationship. The learning group is composed of people who use different mother tongue teaching, and the emphasis is on autonomy, that is, learners organize their learning process in a coordinated way. Teachers act as learning advisor roles to help autonomous learners formulate learning strategies appropriate to them. This way of learning is the learning process of the learners themselves, and the teachers provide learners with learning scenarios and suggestions

\section{METHOD OF ADJUSTING STUDENTS' ANXIETY}

\section{A. Train students' self-confidence}

In order to reduce student's anxiety, first of all to help students re-establish self-confidence, so that students can correctly assess themselves. Teachers help students build selfconfidence, some students reflect: "I feel much better now. I thought my English was better than others, and it was hard to catch up with me. Now I know that I have the same learning ability as other students. We are all on the same starting line. If I can make full use of all the resources in the school, I can achieve great results, too." [8].

\section{B. New method of teaching}

In the process of listening teaching, teachers should try to make students form the habit of listening materials, concentrating their attention on content rather than language points. Students should have certain ability of "fault tolerance". Let the students understand that the purpose of listening is to understand the content of the material, not just to pay attention to each word. Otherwise, students will "see the trees and not the forest". Usually in spoken language classes, Chinese students are more vulnerable than children in the West since childhood. They are especially afraid of making mistakes and are being laughed at by other classmates. The teacher can help him imagine a scene. "If a foreigner talks to you and says the wrong thing, will you laugh?". Such a setting can ease student anxiety and make them more daring to practice speaking. In the teaching of English writing, teachers should minimize their interference with students, minimize their compositions, and pay more attention to their writing intention and writing desire. Teachers try to turn English writing into a real need for students to express their feelings and experiences. All of these teaching processes should be carried out in an atmosphere of encouragement. Once the atmosphere builds up, the fear of writing is eliminated. The students will do very well with his writing assignments. Teachers use this method to teach writing, and students will really feel the exchange of ideas and life experiences. In this way, students will regard English as a language to be used, not just a foreign language to deal with exams.

\section{Cooperative learning based on Network}

The development of the Internet has brought new opportunities for the reform and development of College English teaching. The new teaching model should be supported by modern information technology, especially network technology, so that English teaching will not be limited by time and place. The new teaching mode requires students to "experience, practice, participate, cooperate and communicate". Therefore, web-based cooperative learning will inevitably become the trend of current foreign language research and teaching practice.

In the 90 s of last century, foreign countries began to study such topics. At present, computer supported cooperative work platform is widely used both at home and abroad for cooperative learning. This platform is aided by computer and network technology to coordinate and cooperate with each other to accomplish a task. The construction of this platform includes the construction of cooperative work system, the research of group work mode and the related technology research of supporting group work and the development of application system. The electronic teaching platform is usually developed by professional companies and teaching units. The common feature of this system is to provide all the functions that facilitate cooperative learning on a unified platform, such as forums, shared spaces, chat rooms, instant messaging tools, and e-mail. In addition to the above functions, the teaching platform often provides: user management, virtual classroom teaching, process tracking, test management, question base management, online performance books and other Internet platforms can't provide functionality. The system can take centralized training, and learners can easily master the method of using this software. The famous network cooperation platform is used in the world are: 1995 from the beginning of the San Diego State University and developed WebQuest model Dorje March by the British and Columbia Department of computer science development model WebCT.

The research and application of cooperative learning in our country started relatively late, and it is still in the initial stage, and there are still some problems and shortcomings, mainly in the following aspects:(1) The study of cooperative learning mostly stays at the theoretical level, while the empirical research on cooperative learning is not enough, and the application of web-based cooperative learning is not universal enough. (2)According to the teaching practice of the subject, there is little research on the application of cooperative learning to the students under the conventional teaching conditions. The purpose of this paper is to discuss the theory and experiment of cooperative learning under the network environment in combination with the reform and practice of College English teaching. The purpose of this study is to quantify the relationship between student participation in collaborative learning and its effectiveness in a networked environment. The research results can effectively test the feasibility and effectiveness of web-based cooperative learning model in College English teaching, and provide empirical evidence for the application of this model in teaching practice.

\section{Establish correct self-evaluation view}

Teachers should help students face the pressure correctly, that is, how to guide them to evaluate themselves and others correctly. Make students not only compare with other students, but also compare with their own past. When you find that you have made significant progress compared with the past, it can stimulate the students' learning motivation more. Especially for 
those students who have started a long distance from other students, this kind of motivation will become a powerful driving force for them to catch up with other students. In a sense, the comparison between students is motivated by good motivation, and this comparison will play a positive role in promoting students' learning. At the same time, teachers should guide students to form an egalitarian atmosphere in the class, that is to say, not because of relatively good grades students enjoy any privileges, and no students due to the relatively poor performance will be affected by other classmates' discrimination. $[9,10]$.

\section{E. Role transformation}

Teachers should also improve their teaching ideas, and the teaching process should be "student centered"'. The central character of the class should be students, not teachers. Once students feel that they are the main characters in the class, their spirit will relax. Teachers must treat students alike without any favoritism. Teachers should be cautious in class and avoid embarrassing students in front of other students. The teacher's evaluation of students should not rest entirely on the results of an examination, but a comprehensive study of his usual performance, efforts, and the basis of the original combination of factors. Teachers should always pay attention to students' emotional factors and individual differences, and make great efforts to create a relaxed and pleasant teaching environment, and fully embody the "student centered" teaching philosophy.

\section{SUMMARY AND PROSPECT}

In short, in teaching practice, teachers should pay full attention to emotional factors and individual differences in students' language learning process, and students should be fully aware of and sensitive to their emotional problems in learning. Teachers should fully respect the emotional needs of students, use various teaching methods and techniques, and strive to create a harmonious, relaxed, low anxiety classroom environment. At the same time, the teacher guides the students to make full use of the advanced network teaching platform, so that the English teaching process is no longer limited by time and place. In the process of teaching students to fully understand: "experience, practice, participation and cooperation and exchange" ways of learning, guide students to use cooperative learning mode, so that students can better play the potential of language, and constantly improve the level of practical application of language. Teachers in specific teaching process from the following aspects to guide students: First is tried to stimulate students' interest in English learning, to help students form learning motivation. Teachers should realize that the goals of teaching not only include cognitive goals, and pay attention to students' emotional areas. The purpose of teaching is to gradually reduce external control, and increase the process of students' self-control learning. The second, Teachers should create a good learning environment for students, and help students construct the significance of the current knowledge by setting up the situation that meets the requirements of the teaching content and suggesting the clues between the old and new knowledge. The third, Teachers should guide students to learn through experiments, independent inquiry, Cooperation and so on. In the process of teaching, teachers should help students to understand and analyze what they have learned, to give students the freedom to imagine, rather than simply tell students the results or answers, limiting students' thinking.

\section{REFERENCES}

[1] Amold, J. Affect in language learning. Cambridge: Cambridge University Press. 1999.

[2] Bailey,K. "Competitiveness and Anxiety in Adult Second Langage Learning:Looking at and through the Diary Studies",in Seliger and Long(eds.) Classroom Oriented Research in Secong language Acquisition. Mass:Newbury House. 1983.

[3] Young.Dolly.J.”Creating A Low-Anxiety Classroom Environment". Modern Language Journal 75.

[4] Wen Qiufang. English learning strategies [M]. Shanghai foreign language education press,.1996.

[5] Wen Weiping. Research on foreign language learning disabilities [M]. Xi'an. Northwestern University press,.1998.

[6] Yin Guo thought. Non intelligence factors and their training [M].. Zhejiang people's press,.1996.

[7] Isen,A.M. Positive affect. In Dalgeish,T.\&Power,M.(Eds.). Handbook of Cognitionand Emotion. London: John Wiley\&Sons Ltd. 521-539.1999.

[8] Maeleod,C. Anxiety and anxiety disorders. In Dalgeish, T. \& Power, M. (Eds.). Handbook of Cognition and Emotion. London: John Wiley \& Sons Ltd.447- 77. 1999.

[9] Onwugbuzie,A.J.etal. The validation of three scales measuring anxiety at different stages of the foreign language leaming Proeess: the input anxiety scale,the Proeessing anxiety scale, and the output anxiety sceale. Language Learning 50:87-117. 2000.

[10] SPolsky,B. Conditions for Second Language Learning. Shanghai: Shanghai Foreign Languages Education Press. 2000. 